\title{
Angiossarcoma de Mama - Relato de Caso
}

\author{
Angiosarcoma of the Breast - Case Report \\ Renata Silva de Oliveira Viviani, Luiz Henrique Gebrim, Afonso Celso Pinto Nazário, \\ Cláudio Kemp, Geraldo Rodrigues Lima

\section{RESUMO}

\begin{abstract}
O angiossarcoma primário da mama é um tumor raro, que incide entre os 14 e 82 anos, com média aos 35 anos de idade. Seu aspecto clínico predominante é o de uma massa indolor, com aumento difuso na mama, que se apresenta com cor violácea ou enegrecida. Como ocorre com outros tipos de sarcoma, o tamanho médio da lesão é de aproximadamente $5 \mathrm{~cm}$ quando do diagnóstico. Histologicamente, o angiossarcoma caracteriza-se pela proliferação de células endoteliais que formam canais vasculares comunicantes entre si infiltrando estruturas glandulares e o tecido adiposo. Seu diagnóstico histológico é dificil e nem sempre é estabelecido de imediato, principalmente nos casos com baixo grau de malignidade, devido geralmente à escassez do material biopsiado. Pela dificuldade diagnóstica e pela agressividade, trata-se de neoplasia de prognóstico desfavorável pelas freqüentes metástases. Em nosso serviço, uma paciente de 18 anos procurou atendimento por apresentar nódulo doloroso de rápido crescimento, que foi biopsiado com diagnóstico de hemangioma, sendo indicada ressecção ampla. Três meses após, evoluiu com recidiva tumoral, que foi novamente biopsiada sendo indicada mastectomia, por tratar-se de angiossarcoma de baixo grau de malignidade. Após novas recidivas, indicou-se quimioterapia e, posteriormente, radioterapia. Em vigência desta, evoluiu com novas metástases, indo a óbito por metástase pulmonar.
\end{abstract}

PALAVRAS-CHAVE: Sarcoma. Mama: câncer.

\section{Introdução}

O angiossarcoma primário da mama é extremamente raro. A incidência relativa em relação aos sarcomas mamários é de 2,7 a $7,9 \%$. Cerca de $15 \%$ deles acometem as mamas.

A idade no momento do diagnóstico varia de 14 a 82 anos, com média aproximada de 35 anos $^{1}$.

$\mathrm{O}$ aspecto clínico predominante é o de uma massa mamária indolor, às vezes com aumento difuso da mama. A pele suprajacente pode apresentar cor violácea ou enegrecida.

Seu aspecto macroscópico é muito variável, sendo na maioria das vezes uma massa amolecida e hemorrágica com bordos mal delimitados. Entretanto, algumas vezes se manifesta como uma área endurecida ou espessada da mama ${ }^{2}$.

Como nos demais tipos de sarcoma, o diâmetro médio da lesão quando do diagnóstico é maior que 5 centímetros. Vários autores têm observado uma correlação entre o diâmetro do tu$\overline{\text { Disciplina de Ginecologia, Setor de Mastologia - UNIFESP/EPM }}$ Correspondência:

Renata Silva de Oliveira Viviani

Rua Sargento Cid n³45 apto. 104

09030-170 - Santo André - SP

Tel/fax: (11) 4972-3867 mor primário e o prognóstico ${ }^{3}$, sendo que as pacientes com tumores com menos de $3 \mathrm{~cm}$ de diâmetro têm melhor prognóstico quando comparadas àquelas com tumores volumosos ${ }^{2}$.

Sugere-se a possibilidade de estes tumores sofrerem influência hormonal, devido à presença de receptores de estrógeno, progesterona e glicocorticóides ${ }^{2,4,5}$.

Por definição, o angiossarcoma mamário se origina no interior do parênquima, podendo comprometer secundariamente a pele suprajacente ou músculos peitorais em casos avançados. Histologicamente caracteriza-se pela proliferação de células endoteliais, que formam canais vasculares anastomosados entre si e que infiltram as estruturas glandulares e o tecido adiposo ${ }^{6}$. Devido à sua rara incidência e ao freqüente erro no diagnóstico, retardando a terapêutica adequada, relatamos o caso ocorrido em nosso serviço.

\section{Relato de caso}

Paciente com 18 anos, de cor negra, foi atendida no Ambulatório de Mastologia, no Hospital São Paulo, em setembro de 1995 com quei- 
xa de nódulo indolor e aumento de volume da mama esquerda há 3 meses, que evoluiu rápida e progressivamente.

Teve menarca aos 14 anos, era nuligesta e negava uso de anticoncepcional hormonal, bem como história familiar de câncer de mama.

Ao exame físico apresentava à palpação, tumor de $4 \mathrm{~cm}$ nos quadrantes súpero-lateral e súpero-medial da mama esquerda, móvel e regular. Não havia linfonodos axilares palpáveis.

Foi realizada punção com agulha fina, que foi inconclusiva, pela grande quantidade de sangue. Foi então indicada biópsia excisional ambulatorial, com diagnóstico inicial de tumor filodes. O estudo anatomopatológico revelou tratar-se de um hemangioma capilar associado a fibrose.

Quatro meses após, a paciente apresentou tumoração na mama esquerda, de $4 \mathrm{~cm}$ de diâmetro, que ao ultra-som mostrava consistência sólida heterogênea, de contornos não-delimitados, com cistos no interior, que foi tratada por ressecção ampla, tendo o diagnóstico de hemangioma capilar.

Três meses após, apresentou nova recidiva, que foi biopsiada, tendo sido indicada a mastectomia total. O achado macroscópico intraoperatório foi de um tumor esbranquiçado, firme e elástico, permeado por áreas vinhosas irregulares, comprometendo praticamente toda a mama. Foi também feita exérese de parte do músculo peitoral e margem de pele adjacente à lesão. À microscopia, observavam-se lesões vasculares envolvendo difusamente o parênquima mamário, revestidas por endotélio plano com esparso tecido mural destituído de tecido muscular. O estudo imuno-histoquímico (método streptavidina-biotina-peroxidase) foi positivo para fator VIII, vimentina e CD34. Estes achados foram considerados compativeis com angiossarcoma de grau intermediário de malignidade histológica. Foi então realizada revisão das lâminas das biópsias anteriores, concluindo tratarse de lesões compativeis com angiossarcoma de baixo grau de malignidade (Figuras 1, 2 e 3).

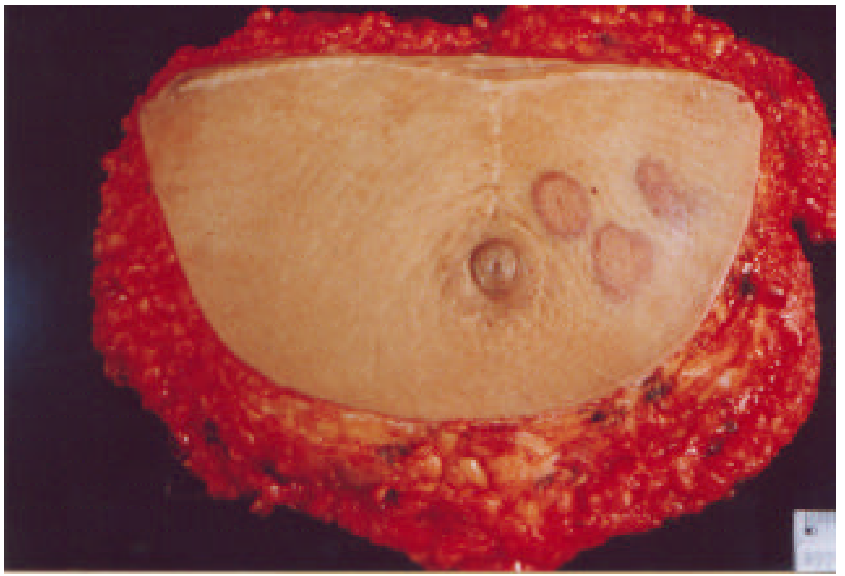

Figura 1 - Recorrência loco-regional vista em peça de mastectomia.

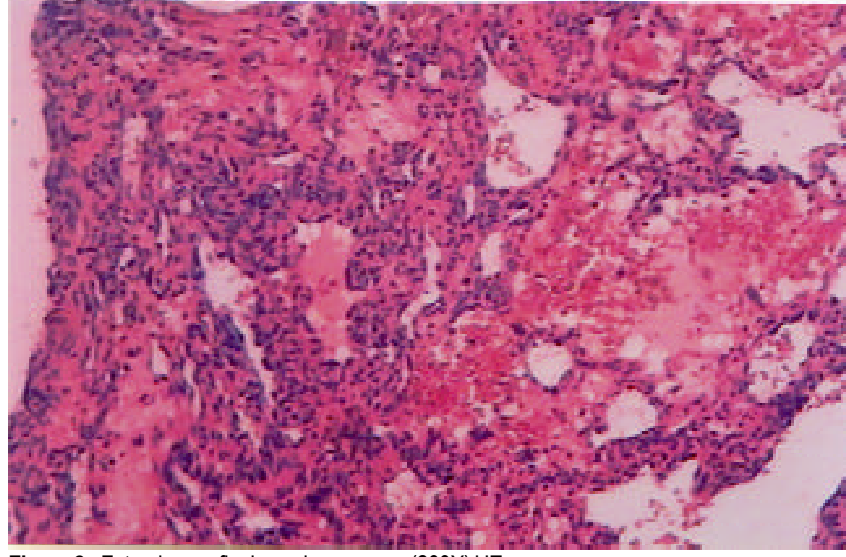

Figura 2 - Fotomicrografia de angiossarcoma (200X) HE.

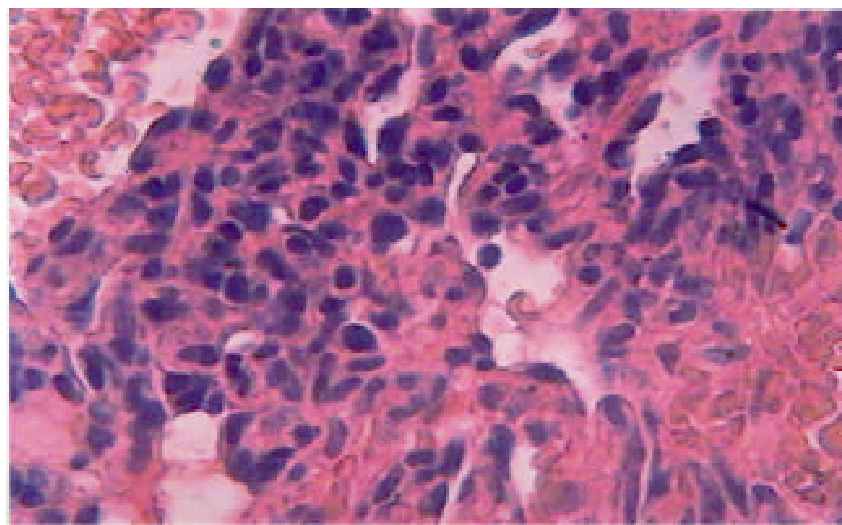

Figura 3 - Fotomicrografia de angiossarcoma (400X) HE. Observar núcleos hipercromáticos.

A paciente evoluiu com nova recidiva na cicatriz cirúrgica, cinco meses após, sendo então iniciada quimioterapia, com 3 ciclos de PAI (cisplatina, doxorrubicina, Mitexan e Holoxane). Em vigência da quimioterapia, detectou-se nova recidiva na cicatriz, sendo indicada exérese da mesma e modificado o esquema quimioterápico para PEB (cisplatina, etoposida e bleomicina), sendo realizados 5 ciclos (Figura 4).

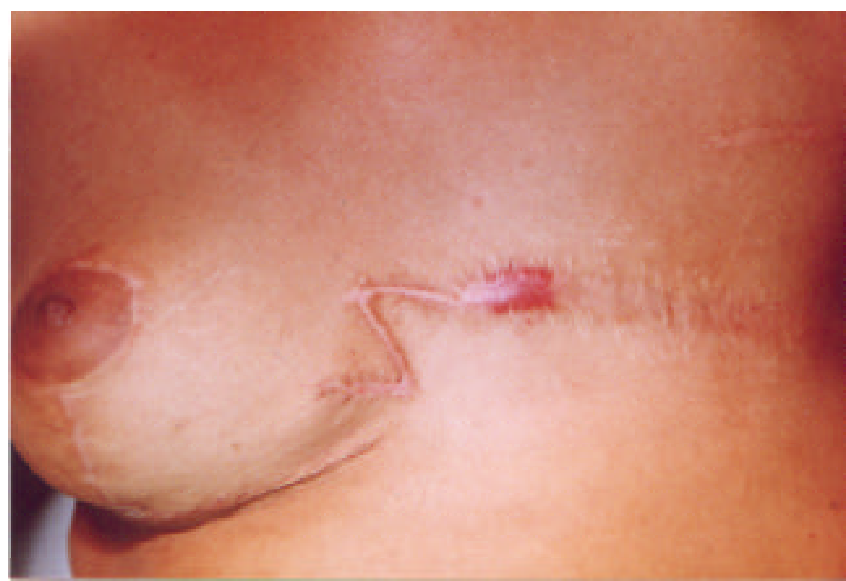

Figura 4 - Recorrência local pós-operatória - área eritematosa na cicatriz cirúrgica. 
Após o $5^{\circ}$ ciclo de PEB, apareceram novos nódulos metastáticos na mama contra-lateral, na região de omoplata esquerda e no quadril direito, que foram excisados, sendo indicada radioterapia bilateral. Foram realizadas 25 sessões, com dose total de 4500 cGy na mama contralateral e na cicatriz.

Três meses após, e em vigência de tratamento radioterápico na região da omoplata, a paciente apresentou dispnéia de início súbito, evoluindo para óbito. Foi diagnosticada metástase pulmonar, que foi confirmada pela necropsia.

\section{Discussão}

O angiossarcoma mamário é raro e nem sempre o diagnóstico de certeza se confirma de imediato, existindo apenas 170 casos relatados na literatura ${ }^{7}$. Grande parte das pacientes, especialmente aquelas com tumores de baixo grau de malignidade, têm o seu diagnóstico retardado devido à escassez de material biopsiado ${ }^{1,8}$. O diagnóstico de certeza só é feito mediante vários fragmentos de tecidos para uma melhor avaliação anatomopatológica.

Uma característica destes tumores é a extensão microscópica, podendo frustar o intuito do cirurgião de extirpar a totalidade da lesão com uma ressecção ampla ${ }^{1,2,4}$.

Os padrões de crescimento do angiossarcoma podem ir desde uma formação de vasos sangüíneos bem diferenciados, até uma proliferação sólida mal diferenciada de células fusiformes, podendo apresentar-se de aspecto benigno ou associar-se a um potencial extremamente anaplásico.

É classificado em 3 categorias $^{2}$, sendo: grupo I ou bem diferenciado - caracteriza-se pela presença de canais vasculares bem formados, anastomosados e infiltrativos que afetam as estruturas glandulares mamárias. A arquitetura glandular mamária se mantém preservada à medida que as estruturas vasculares proliferativas crescem e expandem o estroma intralobular. A atividade mitótica identificável é mínima ou nula. Este padrão de crescimento com um padrão inócuo é o que mais freqüentemente conduz a um diagnóstico de benignidade (hemangioma ou angiomatose); os tumores do grupo II ou intermediários ou moderadamente diferenciados - apresentam atividade mitótica mais freqüente; em alguns casos pode-se identificar tumor sólido ou de células fusiformes, que são características das lesões de alto grau histológico; por fim, no grupo III ou pouco diferenciado estão os tumores que apresentam áreas de crescimento sólido compostas por células fusiformes, com pronunciada atividade mitótica ${ }^{2,9}$.
Os angiossarcomas possuem um aspecto morfológico heterogêneo à microscopia. Associam-se com ampla variedade histológica tanto do lado da mesma lesão, como entre distintos tumores, sendo então, recomendável que todos os tumores vasculares da mama sejam cuidadosamente estudados com uma quantidade suficiente de amostras enviadas ao patologista para descartar proliferações vasculares benignas ${ }^{6}$.

As amostras obtidas mediante punção aspirativa com agulha fina em angiossarcoma mamário se associam com abundante quantidade de sangue e com células tumorais dispersas e dificeis de identificar com certeza. Esta afirmação é especialmente válida nos casos de angiossarcoma de baixo grau, nos quais as células endoteliais malignas mostram uma escassa tendência a proliferar em conglomerados sólidos ${ }^{10}$.

Estudos revisados por Chen et al. ${ }^{1}$ observaram que, de 87 casos revisados, 37\% das lesões haviam sido erroneamente diagnosticadas como linfangiomas e hemangiomas, o mesmo ocorrendo em 2 dos 8 casos revisados por Molitor et al. $^{8}$ e, no caso relatado por Macias-Martinez et al. ${ }^{6}$.

Um fenômeno significativo que ocorre nestes tumores é a presença de um padrão de lesão bem diferenciada (grupo I) na borda periférica infiltrativa presente em praticamente todos os angiossarcomas mamários e um componente pouco diferenciado (grupo III), situado com maior freqüência na parte central da lesão ${ }^{2}$.

As técnicas imuno-histoquímicas raramente desempenham um papel útil na classificação patológica do angiossarcoma mamário. Os antígenos relacionados com o fator VIII e com o Ulex eropaeus aglutinina-1 (UEA-1) são os marcadores das células endoteliais normais e neoplásicas, mas que podem não ser encontrados nos casos das células endoteliais neoplásicas menos diferenciadas. No entanto, a identificação destas substâncias nas células neoplásicas vasculares não permite estabelecer uma diferença entre processos benignos e malignos ${ }^{9,11}$.

O princípio fundamental do tratamento dessa neoplasia consiste na ressecção tumoral ampla, complementada com mastectomia radical. Raramente compromete os linfonodos axilares. Considerando o comportamento muito agressivo e o prognóstico ominoso destes tumores, é recomendável considerar a terapêutica complementar radical.

A radioterapia perioperatória se associa com uma diminuição da probabilidade de recorrência local $^{11}$ de 20 a $50 \%$ das pacientes submetidas a ressecção ampla como único tratamento. A recorrência em outros órgãos ocorre geralmente nos pulmões em $50 \%$ dos casos ${ }^{12,13}$. Portanto, é necessário implementar um tratamento adjuvante efetivo nos casos de sarcoma de alto grau. 
Rosenberg et al. ${ }^{14}$ demonstraram o prolongamento da sobrevida livre de doença com a administração de doxorrubicina e ciclofosfamida depois da ressecção cirúrgica de sarcomas primários.

Donnell et $a .^{2}$, numa série de registros de casos, a mais completa dos últimos anos, observaram um indice de sobrevida livre de doença da ordem de 41 e $33 \%$ em 3 e 5 anos, respectivamente, em um grupo de 40 mulheres. A sobrevida média das pacientes foi de 2 anos. Uma análise correlacionando a sobrevida e a patologia demonstrou diferenças associadas aos graus histopatológicos, sendo a contagem mitótica o fator histológico mais significante para o prognóstico ${ }^{3}$.

A maioria das mulheres com lesões do grupo I encontravam-se vivas (12/13) e 10 delas sem o desenvolvimento de lesões recorrentes, depois de um periodo de 5 anos. Por outro lado, a maioria das pacientes com tumores do grupo III faleceram (14/18). Neste grupo observaram-se duas sobreviventes a longo prazo, depois de serem tratadas com mastectomia e quimioterapia (principalmente com actinomicina D).

Considerando estes dados, e embora o diagnóstico seja raro, o angiossarcoma mamário torna-se a neoplasia de prognóstico mais ominoso de todos os tumores malignos da mama, com uma freqüente extensão metastática fulminante, no curso de 2 a 3 meses.

\section{SUMMARY}

Primary angiosarcoma of the breast is a rare tumor, which appears between 14 and 82 years, with an average of 35 years of age. Its predominant clinical aspect is a painful mass with diffuse increase in the breast and violet or blackened color. Equally to other cases of sarcoma, the medium size of the lesion is approximately $5 \mathrm{~cm}$ at the diagnosis. Histologically, it is characterized by the proliferation of endothelial cells that form vascular channels linked to each other infiltrating glandular structures and fatty tissue. Its histological diagnosis is difficult and not always the right diagnosis is immediately established, mainly in the cases of a low malignancy degree, due to limited biopsy material. Because of the difficult diagnosis and aggressivity, it is a neoplasia with ominous prognosis, due to frequent metastasis. In our service, a 18-year-old patient presented with a painful lump which grew quickly. It was biopsied and a hemangioma was diagnosed, a wide excision being indicated. Three months later, she suffered a tumoral relapse, that was biopsied again and mastectomy was indicated, because it was an angiosarcoma with low degree of malignancy. After other relapses, chemotherapy was indicated and later, radiotherapy. During radiotherapy she developed new metastases, and died of pulmonary metastasis.

KEY WORDS: Sarcoma. Breast neoplasms.

\section{Referências}

1. Chen KT, Kirkegaard DD, Bocian JJ. Angiosarcoma of the breast. Cancer 1980; 46:368-71.

2. Donnell RM, Rosen PP, Lieberman PH, et al. Angiosarcoma and the other vascular tumors of the breast. Am J Surg Pathol 1981; 5:629-42.

3. Naka N, Ohsawa M, Tomita Y, et al. Prognostic factors in angiosarcoma: a multivariate analysis of 55 cases. J Surg Oncol 1996; 61:170-6.

4. Steingaszner LC, Enzinger FM, Taylor HB. Hemangiosarcoma of the breast. Cancer 1965; 18:352-61.

5. Brentani MM, Pacheco MM, Oshima CT, Nagai MA, Lemos LB, Goes JC. Steroid receptors in breast angiosarcoma. Cancer 1983; 51:2105-11.

6. Macias-Martinez V, Murrieta-Tiburcio L, MolinaCardenas H, Dominguez-Malagon H. Epithelioid angiosarcoma of the breast. Clinicopathological, immunohistochemical, and ultrastructural study of a case. Am J Surg Pathol 1997; 21:599-604.

7. Zincone GE, Perego P, Rossi GM, Bovo G. A case of breast angiosarcoma: diagnostic imaging and review of the literature. Tumori 1995; 81:387-96.

8. Molitor JL, Llombart A, Guinebretiere JM, et al. Angiosarcoma of the breast. Apropos of 8 cases and review of the literature. Bull Cancer (Paris) 1997; 84:206-11.

9. Merino MJ, Carter D, Berman M. Angiosarcoma of the breast. Am J Surg Pathol 1983; 7:53-60.

10.Masin M, Masin F. Cytology of angiosarcoma of the breast. A case report. Acta Cytol 1978; 22:162-4.

11.Burgdorf WH, Mukai K, Rosai J. Immunohistochemical identification of factor VIII-related antigen in endothelial cells of cutaneous lesions of alleged vascular nature. Am J Clin Pathol 1981; 75:167-71.

12. Suit HD. Patterns of failure after treatment of sarcoma by radical surgery or by conservative surgery and radiation. Cancer Treat Symp 1983; 2:241-6.

13.Ronsdahl MM, Lindberg RD, Martin RG. Patterns of failure after treatment of soft tissue sarcoma. Cancer Treat Symp 1983; 2:251-8.

14.Rosenberg SA, Tepper J, Glatstein E, et al. Prospective randomized evaluation of adjuvant chemotherapy in adults with soft tissue sarcomas of the extremities. Cancer 1983; 52:424-34. 